\title{
Antibody response of the fish Rutilus rutilus to the metacestode of Ligula intestinalis
}

\author{
M. A. Williams, D. Hoole \\ Department of Biological Sciences, University of Keele, Keele, Staffordshire ST5 5BG, England
}

\begin{abstract}
Double diffusion studies have shown that antibodies specific for the metacestode of Ligula intestinalis (L.) - the causative agent of ligulosis disease - are produced in roach Rutilus rutilus (L.) immunized with crude worm homogenates. The kinetics and specificity of the plaque-forming cell (PFC) response of roach to intraperitoneal injections of worm tegumental homogenates have been studied using the haemolytic plaque assay. Tegumental antigens were tagged onto sheep red blood cells (SRBC) using tannic acid. Worm-specific PFC were found in both pronephros and spleen on the first day post injection (p.i.) and peaked on Day 6 p.i., thereafter falling to background by Day 14. Peak PFC responses in both pronephros and spleen were similar with respect to period p.i. Results suggest that roach are able to produce Ligula tegument-specific antibodies. It remains to be shown whether the worm target antigens are true surface molecules or excretory/secretory products.
\end{abstract}

\section{INTRODUCTION}

In recent years fish immunological studies have been directed towards elucidating the interactions between economically important fish species and their associated viral and bacterial pathogens. Considering the present and future impact of metazoan parasites on world-wide pisciculture and the fact that many helminths which infect fish are also human pathogens, e.g. Diphyllobothrium latum, it is perhaps surprising that the immunological interactions between fish and this group of parasites have not been extensively studied.

Ligula intestinalis, the causative metacestode of the disease ligulosis, infects a variety of fish species. Numerous ecological and pathological studies have revealed that the parasite can seriously affect the population dynamics of both wild fish (Wilson 1971, Kennedy \& Burrough 1981) and those involved in aquaculture (Xianghua \& Zhixin 1987).

In Britain the plerocercoid of Ligula intestinalis (L.) (Cestoda: Pseudophyllidea) occurs in the body cavity of the cyprinid intermediate host. Usually, as in roach Rutilus rutilus (L.), ligulosis is associated with an intense cellular response, the components of which have been described by Arme \& Owen (1970) and Hoole \& Arme $(1982,1983 \mathrm{a}, \mathrm{b})$. However, in gudgeon Gobio gobio (L.) a cellular response is not elicited. This differential response may result from the aquisition of host proteins on the parasite surface (Hoole \& Arme 1983b) and/or the respective immune interactions between the parasite and its hosts (Taylor \& Hoole 1989, Taylor 1990).

Humoral components of the immune response to Ligula have not been extensively investigated. Although in vitro studies using roach have led to speculations on the role of complement (Hoole \& Arme 1986) and C-reactive protein (Hoole \& Arme 1988) in the immune response to ligulosis in vivo, the possible role of antibody remains unclear. Molnar \& Berczi (1965) used the Ouchterlony double diffusion technique to demonstrate the presence of worm-specific antibodies in naturally ligulosed bream Abramis brama (L.). However, Sweeting (1977) failed to find specific antibodies in serum from ligulosed roach using double diffusion, though electrophoretic studies showed an increase in the gamma globulin fraction of sera from ligulosed fish compared to non-ligulosed fish. Inhibition studies by Hoole \& Arme (1988) did not discount the possibility of anti-phosphorylcholine antibodies playing a role in leucocyte adherence to the plerocercoid surface.

To demonstrate whether indeed roach do produce antibodies against Ligula, an Ouchterlony double diffusion technique was carried out using immunized fish. In addition, the kinetics and specificity of the antibody- 
producing cell response in the lymphoid organs was determined using a haemolytic plaque assay.

\section{MATERIALS AND METHODS}

Double diffusion. Fish: Non-ligulosed roach, mean weight $210 \mathrm{~g}$, were obtained from Blithfield Reservoir, Staffordshire (England). Fish were maintained in dechlorinated, aerated tapwater at $20^{\circ} \mathrm{C} \pm 1 \mathrm{C}^{\circ}$ and fed on commercial fish meal. Ligulosed fish obtained from Highfield Pool, Nottinghamshire, were maintained in water at an ambient temperature of 9 to $12^{\circ} \mathrm{C}$. Fish were acclimated for at least 2 wk prior to experimentation.

Preparation of homogenates: Crude homogenates were produced from whole metacestodes. The worms were homogenized in $0.85 \%$ saline using a glass hand-held homogenizer on ice and the resulting homogenates centrifuged at $2000 \times \mathrm{g}$ for $10 \mathrm{~min}$ at $4{ }^{\circ} \mathrm{C}$. The supernatants were removed and frozen at $-20^{\circ} \mathrm{C}$ until used.

Immunization regime: Non-ligulosed fish were intraperitoneally (i.p.) injected with $0.2 \mathrm{ml}$ of either saline in Freunds Complete Adjuvant (FCA) (1:1) or whole worm homongenate (protein concentration $1 \mathrm{mg}$ $\mathrm{ml}^{-1}$ ) in FCA (1:1) on Day 0 and again 9 d later. On Day 20 post primary injection blood was taken by caudal puncture and allowed to clot for $1.5 \mathrm{~h} \mathrm{at} 4{ }^{\circ} \mathrm{C}$. The serum was removed and frozen at $-20^{\circ} \mathrm{C}$ overnight.

Preparation of gels: Gels were prepared using $1 \%$ Agarose 10 in phosphate buffered saline (PBS), $\mathrm{pH} 7.2$. $10 \mu \mathrm{l}$ well $^{-1}$ of sera, obtained from immunized roach kept at $20^{\circ} \mathrm{C}$, and homogenates were allowed to diffuse for $3 \mathrm{~d}$ in a humidity chamber kept at room temperature $\left(20^{\circ} \mathrm{C}\right)$ after which gels were stained with Coomassie Brilliant Blue.

Haemolytic plaque assay. Fish: Non-ligulosed roach, mean weight $33.5 \mathrm{~g}$, were obtained from Highfield Pool, Nottinghamshire (England). Fish were maintained as previously described at 9 to $12^{\circ} \mathrm{C}$.

Preparation of homogenates: A crude worm tegumental antigen preparation was obtained by manually stripping away the tegument and homogenizing as previously described.

Inmunization regime: Fish were either given a single i.p. injection of $0.2 \mathrm{ml}$ Ligula crude tegumental homogenate (protein concentration $0.3 \mathrm{mg} \mathrm{ml}^{-1}$ ) in FCA $(1: 1)$ or $0.2 \mathrm{ml}$ of saline in FCA $(1: 1)$.

Preparation of target cells and lymphoid cells: Sheep red blood cells (SRBC) in Alsevers' solution (ICN Flow) were washed 3 times in $0.85 \%$ saline and Ligula antigens attached by tanning according to the method of Stavitsky (1954). Briefly, after removal of the supernatant, the washed SRBC were added to a 40 times volume of buffered saline (pH 7.2). A 1:20 000 dilution of tannic acid was then added to this mixture (1:1) and the whole incubated for $10 \mathrm{~min}$ at $37^{\circ} \mathrm{C}$. The cells were then washed as previously described and resuspended in saline.

Tanned SRBC were incubated for $10 \mathrm{~min}$ at room temperature (ca $20^{\circ} \mathrm{C}$ ) with an equal volume of tegumental homogenate and a 4 times volume of buffered saline ( $\mathrm{pH}$ 6.4). The suspension was washed 3 times and the concentration adjusted to $2 \times 10^{9}$ cells $\mathrm{ml}^{-1}$.

Pronephroi and spleens were removed from control and immunized fish under sterile conditions. Each tissue was pressed through a sterile steel gauze (pore size $0.3 \mathrm{~mm}$ ) using a glass rod. The resulting cell suspension was collected in a small volume of $90 \%$ Leibovitz (L-15) culture medium (ICN Flow) and adjusted to give a final concentration of $2 \times 10^{7}$ leucocytes $\mathrm{ml}^{-1}$. Cell viability was assessed using the Trypan Blue dye exclusion test.

Plaque assay: Monolayer slides were made according to the method of Majoor et al. (1975). Briefly, glass coverslips $(18 \times 18 \mathrm{~mm})$ were secured to precleaned microscope slides $(76 \times 26 \mathrm{~mm})$ by 2 strips of doublesided sticky tape.

Equal volumes of SRBC and fish leucocytes were mixed with serum obtained from non-ligulósed roach (1: 200 dilution) and placed onto the slides. After incubation in a humidity chamber for $2 \mathrm{~h}$ at room temperature slides were viewed using a binocular microscope at low magnification. Only 'obvious' plaques, i.e. those containing a central lymphocyte, were counted.

Three different types of assay were conducted on each tissue. Tissues from worm-injected fish were tested against worm-tagged SRBC (experimental Group A) and also against untagged SRBC (control Group B). Saline-injected fish were tested only against worm-tagged SRBC (control Group C).

Preliminary experiments indicated that fish responded within the first week post injection (p.i.). Assays were therefore concentrated around this period and carried out on Days 1, 2, 3, 4, 6, 10, 14, 21, 28 and 35 p.i.

Plaque-forming cell numbers are expressed as a percentage of the total number of leucocytes and the results statistically evaluated using a paired $t$-test (Group A with B) and an ANOVA (Group A with C).

\section{RESULTS}

\section{Double diffusion}

Precipitin bands were present between the wells containing parasite homogenate and sera from homogenate-injected fish (Fig. 1). Bands were not seen in assays using sera from saline-injected fish. 


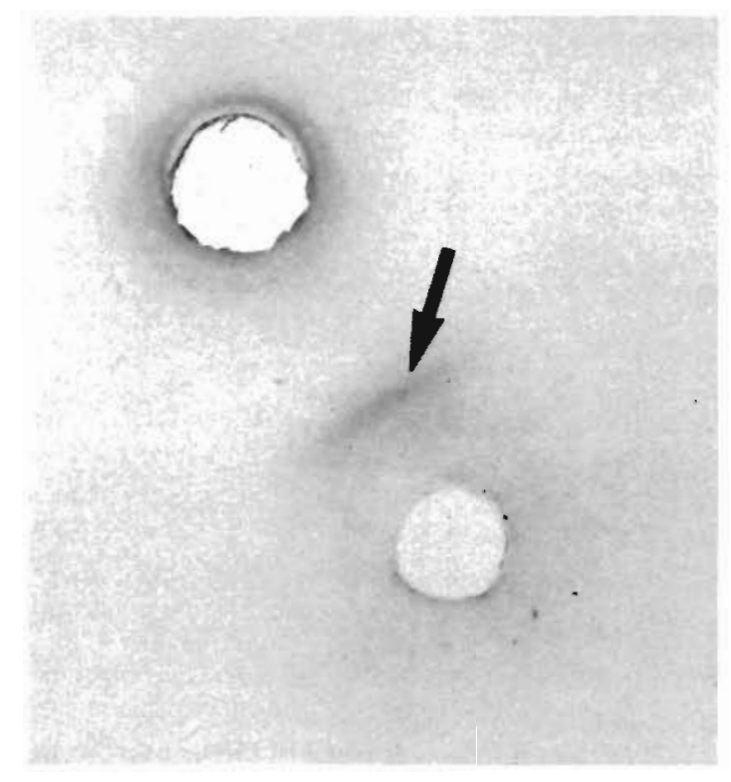

Fig. 1. Double diffusion in agar gel. Upper well contains crude whole metacestode homogenate; lower well, serum from fish i.p. injected with whole-worm homogenates. Note precipitin band between wells (arrowed)

\section{Haemolytic plaque assay}

Viability of cells isolated from the pronephros and spleen were 95.7 and $94.5 \%$, respectively.

Plaque-forming cells (PFC) (Fig. 2) first appeared on Day 1 p.i. in both the pronephroi and spleens of homogenate-injected and control fish.

\section{Pronephric response}

The pronephric responses are shown in Figs. 3 to 5 Each point represents the mean of 6 fish assayed \pm 1 SEM.

The response of Group A fish peaked sharply at Day 4 p.i. and thereafter fell back to reach background levels by Day 14 (Fig. 3). In contrast, the response of Group C fish peaked earlier at Day 3 p.i. with the number of PFC rising to only $30 \%$ of those of Group $\mathrm{A}$ (Fig. 4). There were significant differences in the magnitude of the responses between the 2 groups $(F=6.28$, $p<0.001$ ) and also in the response of the tissues with respect to the period p.i. $(F=13.39, p<0.001)$. A large interaction effect was also noted $(F=5.66, \mathrm{p}<0.001)$ showing that the timing of the responses was significantly different between the 2 groups.

Group B fish showed a pronephric response of PFC that peaked at Day $10 \mathrm{p}$.i. and was maintained at a significantly higher level than that of Group A fish ( $t=$ -5.11, p $<0.001$ ) (Fig. 5).

\section{Splenic response}

Splenic responses are shown in Figs. 6 to 8 . Each point represents the mean of 6 fish assayed \pm 1 SEM.

The response of Group A fish peaked sharply at Day 4 p.i. and fell to background by Day 14 whilst Group C fish peaked earlier at Day 3 p.i. and fell to background by Day 6 (Figs. $6 \& 7$, respectively). The magnitude of response was significantly different overall between

Fig. 2. Typical haemolytic plaque. Note central lymphocyte or plaque-forming cell (large arrow) and SRBC ghosts within the clear plaque area (small arrow)

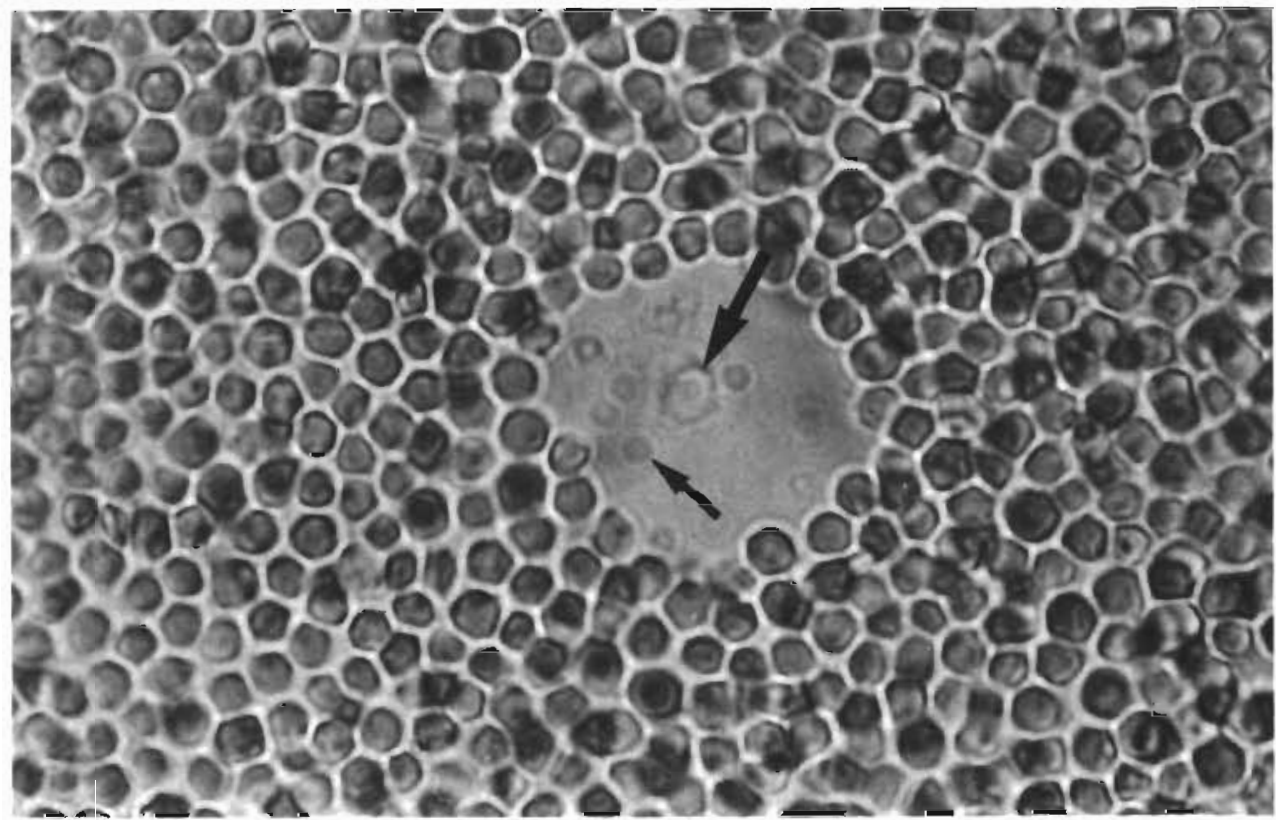




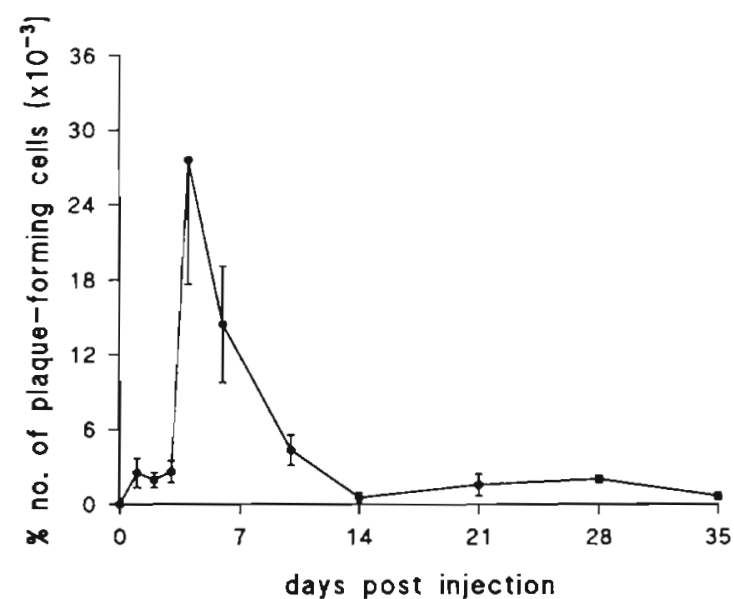

Fig. 3. Pronephric PFC response of experimental fish (Group A), i.e. fish receiving an injection of worm homogenates and assayed against worm antigen-tanned SRBC

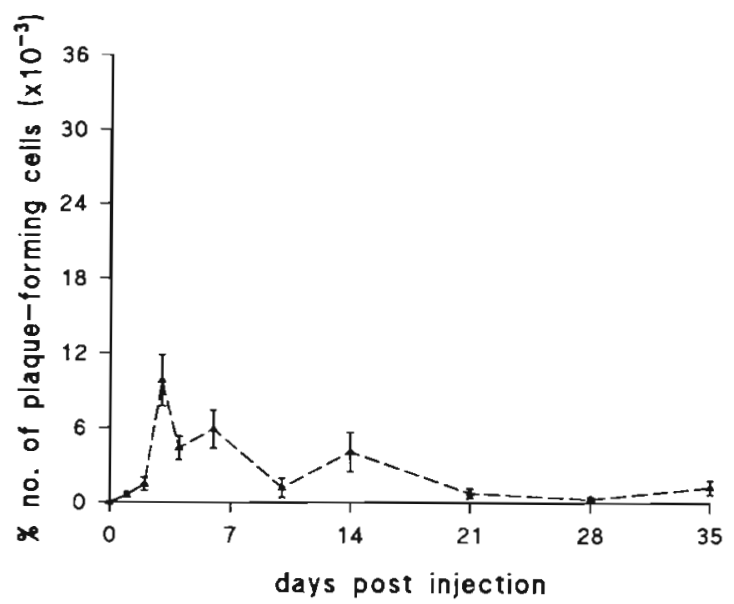

Fig. 4. Pronephric PFC response of control fish (Group C), i.e. fish receiving an injection of saline and assayed against worm antigen-tanned SRBC

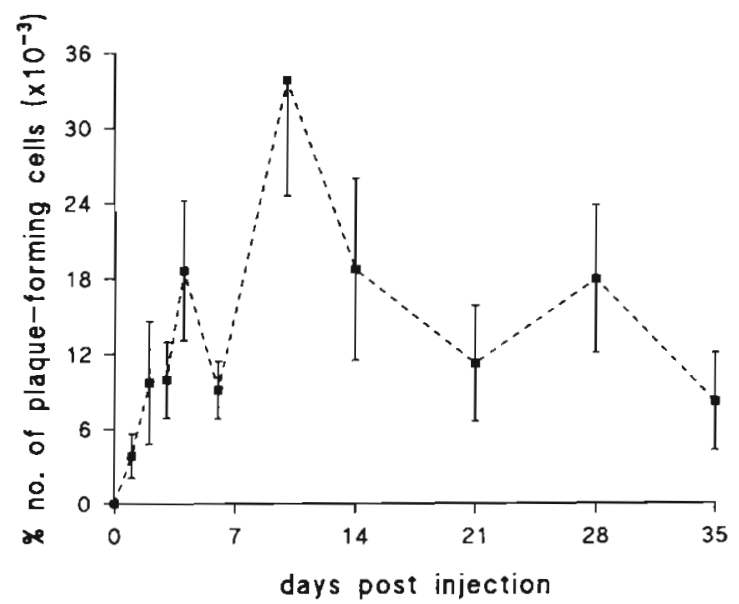

Fig. 5. Pronephric PFC response of experimental fish (Group $B)$, i.e. fish receiving an injection of worm homogenates and assayed against normal SRBC

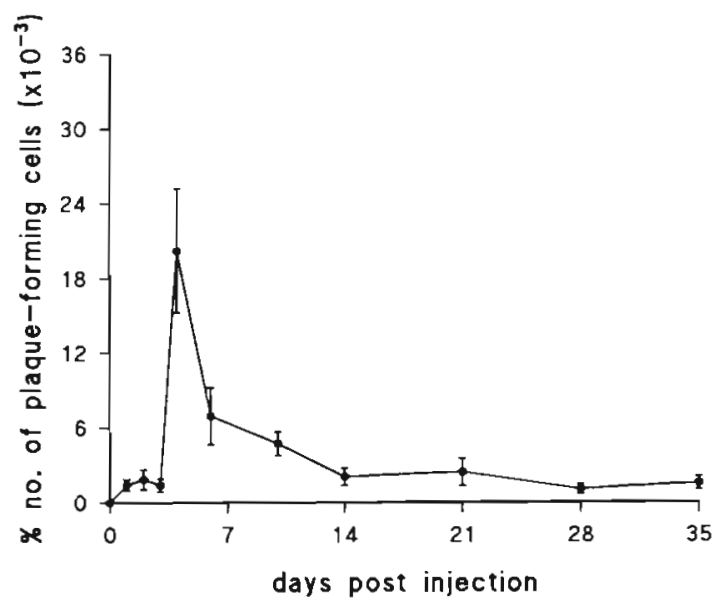

Fig. 6. Splenic PFC response of experimental fish (Group A), i.e. fish receiving an injection of worm homogenates and assayed against worm antigen-tanned SRBC

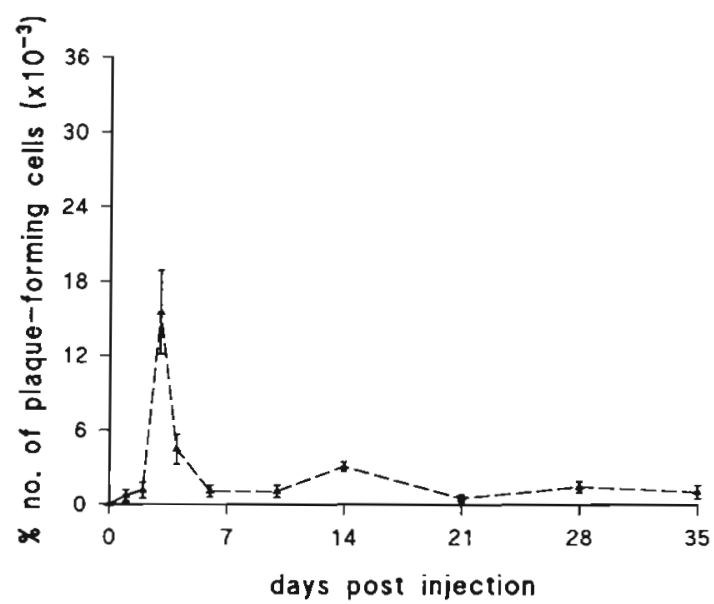

Fig. 7. Splenic PFC response of control fish (Group C), i.e. fish receiving an injection of saline and assayed against worm antigen-tanned SRBC

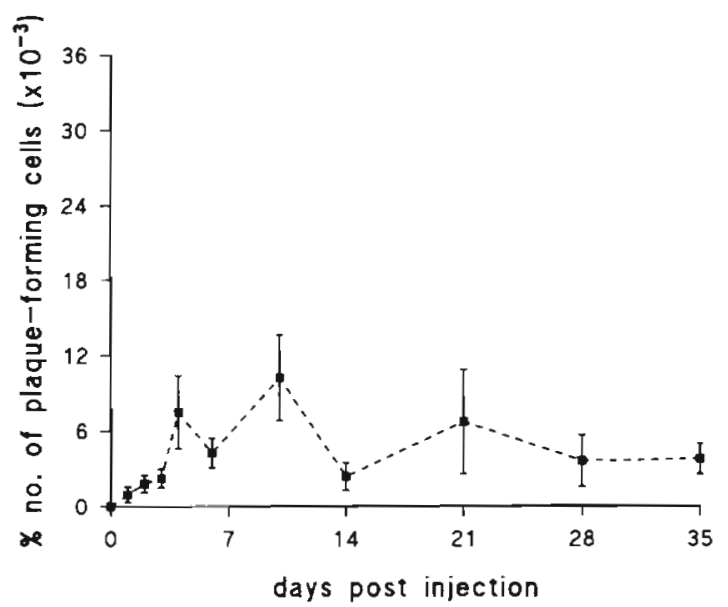

Fig. 8. Splenic PFC response of experimental fish (Group B), i.e. fish receiving an injection of worm homogenates and assayed against normal SRBC 
these 2 groups $(F=6.94, p<0.01)$. The tissues responded differently throughout the period p.i. $(F=$ 11.26, $p<0.001)$, and an interaction effect $(F=9.34$, $p<0.001$ ) shows a significant difference in the timing of the responses between the tissues.

No significant overall difference was found between the splenic responses of Group A (Fig. 6) and Group B (Fig. 8) fish ( $t=-0.04, \mathrm{p}=\mathrm{NS}$ ) although, as in the pronephric response, Group B peaked at Day 10 p.i. compared to a peak at Day 4 for Group A. In all assays a small residual number of PFC were present at $35 \mathrm{~d}$ p.i.

\section{DISCUSSION}

By immunizing Rutilus rutilus with worm homogenates and raising the water temperature the roach were shown to produce worm-specific precipitating antibodies (Fig. 1). In pertinent studies Sweeting (1977) made no reference to water temperature or duration of infection of ligulosed fish. Since the immune response of poikilothermic vertebrates is temperature dependent (Rijkers et al. 1980, Ellis 1982) lower water temperatures would result in a lower antibody response. Sweeting (1977) noted an increase in the gammaglobulin fraction of sera obtained from naturally ligulosed roach when compared to sera from non-ligulosed individuals. This may suggest that antibodies were present at levels too low to be detected by double diffusion.

Indeed our haemolytic plaque assays also indicate the presence of Ligula-specific antibodies in immunized fish. The timing of peak PFC response is dependent both upon the nature of the antigenic material injected (i.e. saline and tegumental homogenates) and the assay antigen presented on the SRBC surface (i.e. normal SRBC and worm-antigen tanned SRBC), but independent of the lymphoid tissue from which the $\mathrm{PFC}$ originate. Based on the percentage of the total leucocyte count the magnitude of response is dependent upon the tissue of origin of the PFC as well as the nature of injected material and the target antigens presented on the surface of the SRBC.

The differences in the timing of peak response between Groups A and B within a given tissue, Days 4 and 10 respectively, cannot be attributed to a different route of entry of antigen in the 2 groups since both received identical injections. It is suggested therefore that the time difference is a result of the generation of heterogeneous PFC subpopulations, with antibodies of either different affinities or idiotypes requiring different times for production/secretion.

Kaattari \& Irwin (1985) reported a heterogeneity of PFC subpopulations in the lymphoid organs of coho salmon Oncorhynchus kisutch injected with 0 -antigen extract of Vibrio anguillarum. PFC from the spleen were shown to be more heterogeneous and have a higher affinity than those from the pronephros, and it was concluded that pronephric PFC were more immature than splenic cells. However, no study of temporal differences of response was made and why, in the present study, different subpopulations should appear at different times is not known.

Differences were not observed in the timing of responses between the tissues. Smith et al. (1967) also found no difference in the timing of PFC production between spleen and pronephros of bluegills Lepomis macrochirus given an injection of SRBC, although more PFC were consistently found in the pronephros than in the spleen. Ingram (1987) reported that after 1 injection of brown trout with SRBC, antibody-secreting cells first appeared on Day 3 p.i. in the anterior kidney but not until Day 6 p.i. in the spleen with peak responses in both organs on Day 12 p.i. This is reasonable if one accepts the hypothesis that the pronephros seeds the spleen with the appropriate PFC after antigenic stimulation. These observations are in contrast to the results presented in this paper which shows that PFC appear in low numbers from Day 1 p.i. in both organs.

The presence of PFC in fish that received injections of saline in FCA is indicative of the production of haemolysins (Figs. $5 \& 8$ ). Natural haemolysins in fish sera to heterologous cells have been reported (e.g. Ingram 1987) but the phenomenon is by no means ubiquitous. For example, Smith et al. (1967) found no haemolysin-secreting cells in the lymphoid organs of Lepomis macrochirus before receiving injections or in control fish. It is possible that haemolysins, probably antibodies (Ingram 1987), are cross-reacting molecules stimulated by previously encountered organisms. Indeed, the profile of the pronephric response to untagged SRBC (Fig. 5) appears characteristic of a secondary immune response. Harris \& Cottrell (1976) found antibodies in the sera of plaice Pleuronectes platessa that precipitated with an antigen preparation of an intestinal nematode of the dogfish Scyliorhinus canicula and hypothesised that the nematode may share common antigenic determinants with a micro-organism.

The results of both the double diffusion and the haemolytic plaque assays suggest that antibodies are produced against the metacestode of Ligula intestinalis. Other reports suggest that endoparasitic metazoans stimulate humoral immune responses in fish. The metacercariae of 2 species of Digenea, Cryptocotyle lingua and Rhipidocotyle johnstonei, induced precipitating antibodies in plaice Pleuronectes platessa, though no immune protection against recurrent infections was shown (Cottrell 1977). Immune protection consistent with an antibody mechanism was found in the response of dace Leuciscus leuciscus to the 
pseudophyllidean cestode Caryophyllaeus laticeps which is rejected from the intestine of the fish host in a manner reminiscent of the self-cure mechanism found in the rat-Nippostrongylus system. Attempts to demonstrate the presence of circulating antibody have failed, probably due to the poor sensitivity of the tests employed (Kennedy \& Walker 1969).

Since the advent of the ELISA technique for measuring small amounts of antibody a more accurate quantification of antibody responses has been possible. Whyte et al. (1987) found specific antibodies in rainbow trout Oncorhynchus mykiss sera to the cercarial and diplostomule stages of the digenean Diplostomum spathaceum after immunization with a sonicated antigen preparation. Specific antibodies have also been reported in the serum of naturally infected fish (Bortz et al. 1984). Indeed, in Diplostomum infection immune protection has been demonstrated (Speed \& Pauley 1985).

It has been shown here that roach are able to produce Ligula-specific antibodies. However, the nature of the target antigens, i.e. whether they are true surface molecules or excretory/secretory (ES) products, is not known.

Hoole \& Arme (1986) speculated on the role of antibody in the immune response of roach to Ligula intestinalis when they observed the adherence of fish leucocytes to the metacestode surface in the presence of heat-inactivated immune roach serum. Ultrastructural studies have revealed that the microthrix spines of Ligula are phagocytosed by macrophages and neutrophils (Hoole \& Arme 1986). It is possible that specific antibody has a role in opsonization of the spines but it is not known whether roach leucocytes possess the necessary Fc receptors to facilitate adherence. Fc receptors for IgM have been demonstrated on shark Ginglymostoma cirratum leucocytes but not on the leucocytes of other fish (Haynes et al. 1988). It remains to be seen, therefore, whether worm-specific antibody has a role in protection.

Acknowledgements. We would like to thank the Severn Trent Division of the NRA for allowing the netting of Highfield Pool, Nottinghamshire, and also Blithfield Anglers for supplying fish from Blithfield Reservoir. Funding was gratefully received from the NERC, grant ref. no. GT4 88-ALS 15.

\section{LITERATURE CITED}

Arme, C., Owen, R. W. (1970). Observations on a tissue response within the body cavity of fish infected with the plerocercoid larvae of Ligula intestinalis (L.) (Cestoda: Pseudophyllidea). J. Fish Biol. 2: 35-37

Bortz, B. M., Kenny, G. E., Pauley, G. B., Garcia-Ortigoza, E. Anderson, D. P. (1984). The immune response in immunized and naturally infected rainbow trout (Salmo gairdnern to Diplostomum spathaceum as detected by enzyme-linked immunosorbent assay (ELISA). Devl. comp. Immun., N.Y 8: 813-822

Cottrell, B. (1977). The immune response of plaice (Pleuronectes platessa L.) to the metacercariae of Cryptocotyle lingua and Rhipidocotyle johnstonei. Parasitology 74: 93-107

Ellis, A. E. (1982). Differences between the immune mechanisms of fish and higher vertebrates. In: Roberts, R. J. (ed.) Microbial diseases of fish. Academic Press, London, p. $1-29$

Harris, J. E., Cottrell, B. J. (1976). Precipitating activity in the sera of plaice, Pleuronectes platessa $\mathrm{L}$. to a helminth antigen. J. Fish Biol. 9: 405-410

Haynes, L., Fuller, L., Churchill Mckinney, E. (1988). FC receptor for shark IgM. Dev. Comp. Immun. 12: 561-571

Hoole, D., Arme, C. (1982). Ultrastructural studies on the cellular response of roach, Rutilus rutilus L., to the plerocercoid larva of the pseudophylidean cestode, Ligula intestinalis. J. Fish Dis. 5: 131-144

Hoole, D., Arme, C. (1983a). Ligula intestinalis (Cestoda: Pseudophyllidea): an ultrastructural study on the cellular response of roach fry, Rutilus rutilus. Int. J. Parasit. 13(4): 359-363

Hoole, D., Arme, C. (1983b). Ultrastructural studies on the cellular response of fish hosts following experimental infection with the plerocercoid of Ligula intestinalis (Cestoda: Pseudophyllidea). Parasitology 87: 139-149

Hoole, D., Arme, C. (1986). The role of serum in leucocyte adherence to the plerocercoid of Ligula intestinalis (Cestoda: Pseudophyllidea). Parasitology 92: 413-424

Hoole, D., Arme, C. (1988). Ligula intestinalis (Cestoda: Pseudophyllidea): phosphorylcholine inhibition of fish leucocyte adherence. Dis. aquat. Org. 5: 29-33

Ingram, G. A. (1987). Haemolytic activity in the serum of brown trout, Salmo trutta. J. Fish Biol. 31 (Suppl. A): 9-17

Kaattari, S. L., Irwin, M. J. (1985). Salmonid spleen and anterior kidney harbor populations of lymphocytes with different B cell repertoires. Devl. comp. Immun., N.Y 9 : 433-444

Kennedy, C. R., Burrough, R. J. (1981). The establishment and subsequent history of a population of Ligula intestinalis in roach Rutilus rutilus (L.). J. Fish Biol. 19: 105-126

Kennedy, C. R., Walker, P. J. (1969). Evidence for an immune response by dace, Leuciscus leuciscus, to infection by the cestode Caryophyllaeus laticeps. J. Parasitol. 55(3): $579-582$

Majoor, G. D., van't Veer, M. B., Zaalberg, O. B. (1975). Quick and easy production of monolayer plaque assay slides. $\mathrm{J}$. Immun. Meth. 7: 301-304

Molnar, K., Berczi, I. (1965). Nachweis von parasitenspezifischen Antikörpern im Fischblut mittels der Agar-GelPrazipitationsprobe. Ztschr. Immun. Allergie-Forsch. 129: 263-267

Rijkers, G. T., Frederix-Volters, E. M. H., van Muiswinkel, W. B. (1980). The immune system of cyprinid fish. Kinetics and temperature dependence of antibody-producing cells in carp (Cyprinus carpio). Immunology 41.91-97

Smith, A. M., Potter, M., Merchant, E. B. (1967). Antibodyforming cells in the pronephros of the teleost Lepomis macrochirus. J. Immunol. 99: 876-882

Speed, P., Pauley, G. B. (1985). Feasibility of protecting rainbow trout, Salmo gairdneri Richardson, by immunizing against the eyefluke Diplostomum spathaceum. J. Fish Biol. 26: 739-744

Stavitsky, A. B. (1954). Micromethods for the study of proteins and antibodies. 1. Procedure and general applications of haemagglutination and haemagglutination-inhibition 
reactions with tannic acid and protein-treated red blood cells. J. Immunol. 72: 360-375

Sweeting, R. A. (1977). Studies on Ligula intestinalis: some aspects of the pathology in the second intermediate host. J. Fish Biol. 10: 43-50

Taylor, M. J. (1990). Immunoparasitological studies on Ligula intestinalis (Cestoda: Pseudophyllidea) in roach (Rutilus rutilus) and gudgeon (Gobio gobio). Ph.D. thesis, University of Keele

Taylor, M. J., Hoole, D. (1989). Ligula intestinalis (L.) (Cestoda: Pseudophyllidea): plerocercoid-induced changes in

Responsible Subject Editor: W. Körting, Hannover, Germany the spleen and pronephros of roach, Rutilus rutilus (L.), and gudgeon, Gobio gobio (L.). J. Fish Biol. 34: 583-596

Whyte, S. K., Allan, J. C., Secombes, C. J., Chappell, I. H. (1987). Cercariae and diplostomules of Diplostomum spathaceum (Digenea) elicit an immune response in rainbow trout, Salmo gairdneri Richardson. J. Fish Biol. (Suppl. A): $185-190$

Wilson, R. S. (1971). The decline of a roach Rutilus rutilus (L.) population in Chew Valley Lake. J. Fish Biol. 3: 129-137

Xianghua, L., Zhixin, L. (1987). Distribution of Ligulid tapeworms in China. J. Parasitol. $73: 36 \cdot 48$

Manuscript first received: May 21, 1991

Revised version accepted: September 19, 1991 